Int. J. Electrochem. Sci., 12 (2017) 5910 - 5920

\title{
Synthesis of Multi Walled Carbon Nanotubes Covered Copper Oxide Nanoberries for the Sensitive and Selective Electrochemical Determination of Hydrogen Peroxide
}

\author{
Chieh Yang, Rajkumar Devasenathipathy ${ }^{*}$, Karuppasamy Kohila rani, Sea-Fue Wang*, \\ Department of Materials and Mineral Resources Engineering, No. 1, Sec. 3, Chung-Hsiao East Rd., \\ National Taipei University of Technology, Taipei, Taiwan \\ *E-mail: chemrackz@gmail.com
}

doi: $10.20964 / 2017.07 .87$

Received: 26 March 2017 / Accepted: 19 May 2017 / Published: 12 June 2017

\begin{abstract}
Multi walled carbon nanotubes covered Copper oxide nanoberries (CuONBs/f-MWCNTs) was prepared via simple chemical method. Field emission scanning electron microscopy (FESEM) and energy-dispersive X-ray spectroscopy (EDX) were used to study the surface morphology and elemental composition of our prepared composite. The crystal structure of the composite was analyzed by X-ray diffraction spectroscopy (XRD). The prepared composite was coated at glassy carbon electrode (GCE) and applied for the electro-reduction of $\mathrm{H}_{2} \mathrm{O}_{2}$. CuONBs/f-MWCNTs/GCE works in a wide linear range from $5 \mu \mathrm{M}$ to $10.5 \mathrm{mM}$. The limits of detection (LOD) and sensitivity values are evaluated to be $0.78 \mu \mathrm{M}$ and $1100 \mu \mathrm{A} \mathrm{mM} \mathrm{mm}^{-1}$. $98.3 \%$ of steady state current response was attained within $3 \mathrm{~s}$ by our sensor. The high selectivity of $\mathrm{CuONBs} / f$-MWCNTs/GCE was evident from the interference studies in presence of various biomolecules. Clinical cleaning lens solutions and urine samples were used for the practical feasibility sensor. Our modified electrode can find its significance in near future applications of biosensing research and energy storage devices due to simple fabrication procedure, excellent electrocatalytic activity with good repeatability and reproducibility as well as better practical feasibility.
\end{abstract}

Keywords: Copper oxide nanoberries, FESEM, XRD, Cyclic voltammetry, Rotating disc electrode, Amperometry, Hydrogen peroxide

\section{FULL TEXT}

(C) 2017 The Authors. Published by ESG (www.electrochemsci.org). This article is an open access article distributed under the terms and conditions of the Creative Commons Attribution license (http://creativecommons.org/licenses/by/4.0/). 